hardly be taken as an explanation; it means no more than that the multiplication of the parasites produces more parasites."

From these remarks it is quite evident that our explanation of the increase and decrease of trypanosomes has been entirely misunderstood. In the first place, we do not disagree with the explanation of Massaglia, \&c. ; in the second place, we do not give the alternative explanation that "the increase of parasites is due to their sudden and active development." We have, I think, given our explanation quite clearly in the last page of our article, which I cannot do better than quote, as follows :-

It would seem, therefore, that the explanation may be reduced to some of the following causes, all of which mav come into play.

1. The increase of trypanosomes is due to their active multiplication, the rate of multiplication depending on the following conditions: the rate of multiplication depending on the following conditions (a) The liberation of a reproductive stimulant from the trypanosomes of the previous fall. (b) The small number of leucoeytes, especially mononuclears. (c) The habituation of the trypanosomes to their antitrypanosomes.

$(a),(b),(c)$, and $(d)$ are therefore our explanations of the increase of trypanosomes. $(c)$ and $(d)$ are Massaglia's explanations. (a) and $(b)$ are, so far as we know, original further hypotheses put forward by Major Ross and myself. In a somewhat similar way we explain the decrease of trypanosomes. Again, in the criticism of Article 3 by H. B. Fantham and J. G. Thomson it is stated that "the authors, unlike the authors of the preceding paper, attribute the periodicity to variations in resistance on the part of the host, probably due to the formation of antibodies," \&c. Here, again, I would like to point out that the authors of Article 3 do not disagree with our bypotheses regarding the periodicity. Their work was intended to confirm and extend the information obtained in our research, and the fact that they found rounded bodies in the internal organs, during the fall in the number of trypanosomes, does not contradict any of our explanations. - I am, Sir, yours faithfully,

D. THomson.

School of Tropical Medicine, Liverpool, May 16th, 1911.

\section{GENIUS AND INSANITY.}

\section{To the Editor of THE LANCET.}

SIR, - In his recent and highly instructive lecture ${ }^{1}$ Dr. Mott leaves undecided the vexed question as to the correlation of genius and insanity. To those who are disciples of the Mendelian hypothesis of the transmission of unit-characters, the elucidation of the problem is simple. A unit-character is unsplittable and unblendable. As Professor Punnett puts it: "The individual is an aggregate of unit-characters, and individuality is the expression of a particular aggregation of such characters. Though often reacting upon one another, the factors on which these characters are based behave as independent entities during the hereditary process, and heredity in consequence we may regard as a method of analysis, enabling us to judge of the number and condition of the unit-characters which go up to make the individual." Viewing the matter in this light, there is no necessary correlation of genius and insanity, for each unit-character may be derived from a different source, and this appears to be the solution of those cases of genius combined with insanity, the ancestral data of which are available for scientific investigation.

To advert to another matter discussed in the same lecture, it is somewhat surprising to find Dr. Mott accepting as a fact the alleged epilepsy of Julius Cæsar. What are the facts? The external evidence is mere rumour, and amounts to what Lord Beaconsfield would have stigmatised as bar-parlour talk. What of the internal evidence? Julius Cæsar was the greatest man of the Roman world, and had to deal with problems that would turn the brain of the modern politician. He was a great general, a far-seeing statesman, an eminent man of letters, and as an orator he was reckoned by his contemporaries to be second to Cicero alone. Is all this compatible with classical epilepsy? Yet Dr. Mott on such flimsy evidence proceeds to build up a neurotic pedigree " beginning with the great Julius, an epileptic, and ending with Nero." Of such stuff dreams are made of. But assuming for the sake of argument that Cæsar was afflicted with the morbus comitiahn (as it was then called), is it not more reasonable to suppose that the condition was of the nature of Jacksonian epilepsy, the result of a wound received in battle? This, however, as an acquired character, would have no significance in heredity.

Dr. Mott also claims Napoleon as an epileptic. There is no historical evidence of Napoleon having had "fits" until after his escape from Elba. He was then $46 !$ We have, however, the testimony of his medical attendants that in later life his normal pulse-rate was 40. This would suggest that the so-called epileptic seizures were in reality attacks of " heart block" (Stokes-Adams disease). It is known that the petit caporal was a veritable Don Juan, and likely enough he had contracted syphilis-a disease very prevalent on the Continent at that time.

I am, Sir, yours faithfully,

Wimpole-street, W., May 15th, $1911 . \quad$ KENNETH CAMPBELL.

\section{SOME UNUSUAL EFFECTS OF PER- FORATED GASTRIC ULCER.}

\author{
To the Editur of THE LANCET.
}

Sir,-In your issue of May 13th, under the abore heading, Dr. W. P. S. Branson and Mr. T. P. Legg describe and depict a case of "pronounced lateral curvature of the spine." The case is so unusual that I venture to comment upon it. By " pronounced lateral curvature" do the authors imply that there was actual bony deformity? Cases of scoliosis are divided into two groups, the postural and the osseous, the distinction between the two depending on whether the deformity entirely disappears when the spine is fully flexed. If it disappears the case belongs to the postural group ; if it does not disappear, to the osseous. An inspection of the photograph (see p. 1274) would apparently show that there was moderate osseous deformity ; but as such photographs are often misleading definite information on this point is required. Assuming, however, that osseous deformity was present, and indeed pronounced osseous deformity, is it clear that it had been produced in 11 months? In a man of the patient's age, namely 37 , the production of such deformity in so short a time is unknown. In adults, after severe operations for empyema, and after fracture of the femur or tibia resulting in shortening of a limb, though postural scoliosis is produced almost at once, osseous scoliosis takes many years to develop, and often never appears at all.

In this case, upon what does the evidence for this very rapid onset of deformity rest ? Merely upon the unsupported statement of the patient, a stoker, who "asserted confidently that the curve was but lately acquired, and attributed it to the attitude of flexion towards the left which his pain had compelled him to assume for many months." Similarly mothers are continually bringing for examination their scoliotic children, and confidently ascribing, as due to a fall last week, a hump as large as a camel's. If there be reliable evidence to show that before the onset of the pain, 11 montins previously, the patient was perfectly straight, it should certainly be published, for the rarity of such a case cannot be questioned. I fear, however, that no such evidence will be forthcoming and that the case must be regarded as one of long-standing scoliosis, complicated by gastric ulcer.

I am, Sir, yours faithfully,

London, May 15th, 1911. PAUL B. RotH, F.R.C.S.

\section{INTUSSUSCEPTION IN AN INFANT REDUCED BY AN AIR ENEMA.}

\section{To the Editor of THE LANCET.}

SIR,--There are a few interesting points in the following case which I think make it worth recording. The child was a male and when I first saw it, a week after its birth, was quite up to the average in size and weight for an infant of that age. It was being fed at the breast, and, as the mother told me, was the best child she had ever had and did not give the least trouble. It had been suddenly seized with pain early that morning and had since been vomiting all its milk. They produced two napkins which were soiled with what looked like blood and stringy mucus. Inquiry elicited the fact that the last proper motion took place the evening previous about 6 P.M., and that the child vomited for the first time shortly after the pain seized it that morning. The child did not seem to be in any great pain when I saw it but 
every few minutes it vomited a small quantity of bile-stained fluid. The abdomen was soft and on palpation I failed to discover a tumour of any kind. However, whilst palpating in the right iliac region the child became very restless and began to whimper.

I diagnosed the case as one of intussusception, either ileocæcal or ileocolic, and before leaving I told the mother that it would be possibly necessary to open the abdomen in order to put the child right. When I returned a few hours later the condition of affairs was unchanged; the child still continued to vomit bile-stained fluid at intervals, and although it attempted to suck when put to the breast, the smallest quantity of milk was immediately ejected.

The parents absolutely refused to allow an operation, nor would they allow me to give the baby chloroform. I attempted to reduce the intussusception by means of a warm-water enema, but the tenesmus was so great that without an anæsthetic I found this method to be impracticable. I was about to give the case up as hopeless, when I thought I might try the effect of pumping air into the bowel. So I laid the infant upon a pillow in the centre of the kitchen table, and by means of an ordinary Higginson's springe I pumped in air till the abdomen assumed a distinct fulness. As there was no means of ascertaining whether reduction had taken place or not, I returned the child to its mother and left the house fully convinced that under the circumstances there was very little hope of the child living. Nevertheless, when I called the next day I was agreeably surprised on being told that the child had vomited only once or twice since I left on the previous day, and that most of the milk was being retained. The mother showed me a napkin which had recently been soiled with something very like meconium. The next day the napkins were stained a distinct yellow, and the child had ceased to vomit. It is now about 5 months old and looks quite healthy and contented. I do not know if an intussusception has been reduced by an air enema before, bat on this occasion I think the end quite justified the means. I am, Sir, yours faithfully,

Aberdeen, May 7th, 1911. J. WIIsON, F.R.C.S.

\section{THE INTERNATIONAL PLAGUE CON- FERENCE AT MUKDEN.}

(FROM OUR OWN CORRESPONDENT.)

(Continued from $p .1311$.)

\section{Fourth Day (APRIL 6TH).}

Professor Shibayama (Japan) read a paper giving the Results of his Animal Experiments with Strains of Pneumonic Plague Bacillus isolated from the Harbin and Mukden epidemics, which showed that there was little or no connexion between virulence and toxicity. In conclusion, he spoke on the dispersion of the plague bacillus by coughing. It could not be denied that infection from pneumonic plague in this epidemic was conveyed almost without exception from person to person. The following experiments were made under the supervision of Professor Kitasato by Dr. Tojoda and Dr. Jasuda. A plague patient was laid down sideways with his head fixed. Twenty agar plates were laid before his face in different positions and at different distances and the covers were removed. After the patient had coughed the plates were re-covered and placed for two days in the incubator at a temperature of $30^{\circ} \mathrm{O}$. Plague bacilli were developed on three of the plates. A second trial was made and plague bacilli colonies were developed upon four of the plates at distances of 1 foot, $1 \frac{1}{2}$ feet, $2 \frac{1}{3}$ feet, and $3 \frac{2}{3}$ feet. Further experiments were made to ascertain whether animals susceptible to plague conld be easily infected from the neighbourhood of sick people. For this purpose six guineapigs in wire cages were placed at varying distances from the patient. After 12 hours the animals were removed to the laboratory. All remained in perfect health. It seemed, therefore, that infection of animals by inhalation was difficult.

$$
\text { Fifth DaY (APRIL 7TH). }
$$

Dr. KouleCHA (Russia) read a paper on "Morbid Anatomy, Fspecially in Relation to the Mode of Infection in Plague Pneumonia." He bad dissected 28 plague corpses at Harbin and especially noted the modes of infection. From the results of these necropsies and microscopical examination of the tissues he found that pneumonic plague was a septicæmic disease in which a decided overflooding of the blood and the lymphatic system with bacilli could be observed. Infection entered through the mouth, affecting en route the tonsils, mucous membrane of the trachea, bronchi, and neighbouring lymphatic glands, and passed from these into the blood. The lungs would appear to be infected secondarily from the blood. This he inferred from the great accumulation of plague bacilli in the perivascular spaces. Pneumonic plague was a lobar pleuro-pneumonia of hæmatogenic origin, and should be put in the same category as croupous pneumonia.-Dr. FUJINAMI (Japan) confirmed Dr. Koulecha's findings, but said that while it was certain that infection could start from the mouth it could also start from the trachea and bronchi. Masses of bacilli could be found in the perivascular tissues which were introduced by the lymphatic vessels and to such an extent as to give the appearance of an accumulation of carbonaceous material.-Dr. R. P. STRONG (America) asked if in the primary tonsillar cases the epithelium was greatly eroded, to which Dr. Koulecha replied that in one of his sections, on view in the room, such erosion could be seen.--Professor ZABOLOTNY (Russia) said it had not as yet been sufficiently proved how many cases were of hæmatogenous and how many of direct preumonic origin. He agreed with Dr. Fajinami in the question of carbonaceous penetration of the peribronchial glands. In the first stage of plague pneumonia there were no bacilli in the blood.

Dr. KovLECHA's paper was taken out of the order of the subjects in the programme, as the speaker had to return to Harbin. The Conference then returned to the epidemiological section of its work.

Dr. C. T. ANDREW (Ching-wan-tao) read the results of his observations on 3000 living rats in North Ohina, all of the species mus decumanus. He had never found mus rattus. He had noted a seasonal flea prevalence, the highest number of fleas occurring in September, October, and November. Of many thousands of fleas the only species noted was pulex cheopis.-Dr. G. F. PETRIE (Great Britain) had found both pulex cheopis and ceratophyllus unisus among the fleas examined in Mukden.-Professor Kitasato said that of over 30,000 rats examined in South Manchuria 6 per cent. were mus rattus.

Dr. WU Lien-Ten, the President, referred to the observations of some Chinese doctors on his staff at Harbin during the epidemic. It was reported that over 300 pigs and 400 horses and mules had died. These, of course, might have died from other causess but it was a significant fact that the Japanese doctors had found the case of a donkey which had died and had been proved microscopically and culturally to have died from true plague. After further discussion,

Dr. R. A. P. HILt (Peking) read a paper on "The Character of Epidemic Curves as illustrated in Cities and Districts," and showed many charts. Probably only extremes of temperature had much effect. Some of the charts showed a regular wave motion corresponding to the incubation period.

In the afternoon Professor KITASATo took the chair at a Bacteriological Session. The discussion opened on "The Cultural Characteristics of the B. Pestis Isolated in Manchuria." The general opinion was that little or no difference existed between the Harbin and other bubonic strains in bouillon, except that there was perhaps more mucus in the former.-Professor GALEOTTI said that the presence of more or less mucus in the culture depended upon the amount of carbohydrates in the bouillon.

Professor $Z_{A B O L O T N Y}$ spoke upon Agglutination. He said that agglutination was necessary to diagnose the bacillus of plague. He demanded a high standard serum with high agglutination power as being necessary for correct diagnosis. Personally, he did not use the serum of patients, but took the serum of horses immunised with many cultures, and thus obtained this high degree of agglutination.-Dr. STRONG asked if anyone had found agglutinins clinically in the blood serum of patients, and Professor SHIBAYAMA said that there had been three cases in Dairen. They had had 40 c.c. of plague serum and were cured, and agglutination tests were made 45 days afterwards. They then found agglutinations in dilutions of $1-50$ and 1-100 positive.-Dr. MaRTINI (Germany) said that as far as he could remember 